\title{
Microstructure Evolution and Mechanical Property Characterization of 6063 Aluminum Alloy Tubes Processed with Friction Stir Back Extrusion
}

\author{
SUHONG ZHANG, ${ }^{1,2}$ ALAN FREDERICK, ${ }^{2}$ YIYU WANG, ${ }^{2}$ \\ MIKE ELLER, ${ }^{3}$ PAUL MCGINN,${ }^{4}$ ANMING HU, ${ }^{1}$ \\ and ZHILI FENG (1) $1,2,5$
}

\begin{abstract}
1.-Department of Mechanical, Aerospace and Biomedical Engineering, University of Tennessee Knoxville, 1512 Middle Drive, Knoxville, TN 37996, USA. 2.-Materials Science and Technology Division, Oak Ridge National Laboratory, Oak Ridge, TN 37831, USA. 3.-Lockheed Martin Corporation, Bethesda, MD 20817, USA. 4.-Department of Chemical and Biomolecular Engineering, University of Notre Dame, Notre Dame, IN 46556, USA. 5.-e-mail: fengz@ornl.gov
\end{abstract}

Friction stir back extrusion (FSBE) is a technique for lightweight metal extrusion. The frictional heat and severe plastic deformation of the process generate an equiaxed refined grain structure because of dynamic recrystallization. Previous studies proved that the fabrication of tube and wire structures is feasible. In this work, hollow cylindrical billets of 6063-T6 aluminum alloy were used as starting material. A relatively low extrusion ratio allows for a temperature and deformation gradient through the tube wall thickness to elucidate the effect of heat and temperature on the microstructure evolution during FSBE. The force and temperature were recorded during the processes. The microstructures of the extruded tubes were characterized using an optical microscope, energy-dispersive x-ray spectroscopy, electron backscatter diffraction, and hardness testing. The process reduced the grain size from $58.2 \mu \mathrm{m}$ to $20.6 \mu \mathrm{m}$ at the inner wall. The microhardness of the alloy was reduced from 100 to $60-75 \mathrm{HV}$ because of the process thermal cycle.

\section{INTRODUCTION}

Metal extrusion processes provide most of the semi-finished bar, wire, and tubes for various applications. ${ }^{1}$ Friction stir extrusion (FSE) is an emerging extrusion process, initially developed by TWI in $1992 .^{2}$ FSE creates the extrudate by plunging rotating tools into material placed in a die. Tubes and wires are extruded without being melted. Compared with other metal extrusion processes, FSE is novel in that it relies on the intrinsic frictional heating to soften and plasticize the material. The extensive plastic deformation inherent to the process makes it possible to stir, consolidate, and convert the powders, chips, and other feedstock metals directly into useable product forms. Multiple types of raw materials such as solid bar, powder, and even scrap metal can be used. ${ }^{3-6}$ One of the advantages of FSE is its low energy consumption as a metal recyclizing technology compared with the common melting and casting based recycling technologies, ${ }^{7}$ which is substantiated by theoretical analysis, ${ }^{8}$ actual experimental measurement of the energy usage, ${ }^{5}$ and more recent study. ${ }^{4}$

Friction stir back extrusion (FSBE) is a specific form of FSE. ${ }^{2}$ In FSBE, feedstock materials are extruded backward with respect to the tool's plunge direction. Both wires and tubes can be extruded with FSBE on various types of aluminum, magnesium, and copper alloys using machined chips or solid feedstocks. ${ }^{3-6,9-13}$ FSBE can also be used to fabricate composite material if using powder as feedstock material. ${ }^{14,15}$

Another advantage of FSE and FSBE is the equiaxed refined grain structure in the extrudate upon frictional heat and severe plastic deformation. Hence, it has great potential in providing lightweight tubes with enhanced strength and formability in the aerospace and automotive industries. 
FSBE is still in its early stage of research and development for industrial applications. Various aspects of the process such as tool design and process conditions, as well as their influence on the microstructure and resultant properties, are the subject of considerable research. Strain and texture of wire FSBE were studied. ${ }^{16}$ Finite element models and experimental investigation of material flow and heat transfer were conducted as well. ${ }^{17-19}$ Most studies on FSBE of extruding tubes mainly used solid bar as feedstock material. So far, nearly all studies available in the open literature utilize tool settings and process conditions to subject the entire tube cross section to extensive severe plastic deformation. ${ }^{3,6,12}$ To further the understanding of FSBE, this work adopted a different experimental setup in that only the inner wall of a 6063 aluminum alloy tube was subjected to extensive frictional heating and severe plastic deformation. The microstructure changes through the extruded tube thickness were characterized and related to the process conditions such as forces and temperature.

\section{EXPERIMENTAL}

\section{Experimental FSBE Setup}

The essential features of the FSBE setup used in the present study are shown in Fig. 1a. The tool set consists of two parts: a friction stir tool made from MP159 superalloy and a die made from 17-4 PH steel. The FSBE tools are designed to fit into an MTS FSW machine that can generate $89 \mathrm{kN}$ plunge force and $180 \mathrm{~N} \cdot \mathrm{m}$ rotation torque at maximum. The rotating tool is plunged into a hollow feedstock tube, which is different from previous researches ${ }^{6,12,13,20}$ that used solid bar as feedstock. Therefore, only the material near the inner wall of the feedstock tube would be expected to be directly subjected to frictional heating and associated severe plastic deformation in FSBE. Frictional heating is generated at the interface between the rotating tool and inner surface of the billet. As the billet is heated up by the frictional heating, the billet material softens. The plunging action of the tool forces the softened material to flow through the die under extensive severe plastic deformation on the billet inner wall.

For the experiment, hot extruded hollow tubes of AA6063-T6 aluminum alloy were used. The hollow aluminum tubes had initial dimensions of $21.34 \mathrm{~mm}$ outer diameter (OD) and $16 \mathrm{~mm}$ inner diameter (ID). The ID of the extruded tube was the same as the OD of the plunger. Two different plungers were used in the study. One had a $16.8-\mathrm{mm}$ OD, and the other had a 17.5-mm OD for more aggressive extrusion. The billet was deformed into a thin-wall tube and extruded out of the die in the direction opposite to that of the tool (see Fig. 1a).

Direct measurement of the temperature in the processing zone of the extruded material during FSBE was difficult. In this work, the temperature (a)
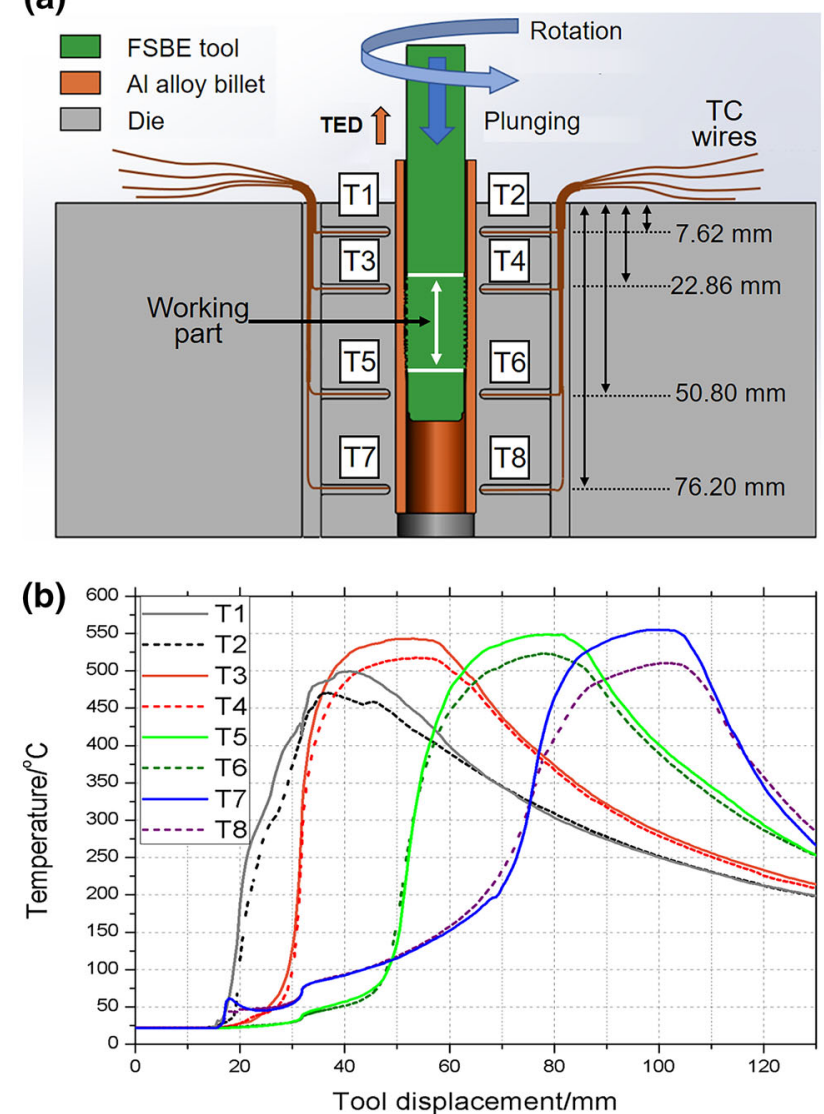

Fig. 1. (a) A schematic drawing of the tools in the FSBE experimental setup in this study. The aluminum tube (orange) extrudes in the direction opposite to the tool plunging direction (backward extrusion), as marked by the arrow labeled "TED." Six sets of thermocouples are located at four depths and at $1 \mathrm{~mm}$ and $1.5 \mathrm{~mm}$ from the tool and extrudate interface. (b) Process temperature data as functions of positions of the thermocouples.

inside the die was measured instead. K-Type thermocouples (TC) were embedded $1.0 \mathrm{~mm}$ for TC $1 \mathrm{~mm}, 3 \mathrm{~mm}, 5 \mathrm{~mm}, 7 \mathrm{~mm}$ and $1.5 \mathrm{~mm}$ for TC 2,4,6,8 (Fig. 1a), respectively, from the die/extrudate interface to provide a reasonable estimate of the temperature inside the extrudate. We note that this technique was also used in friction stir welding research to understand the material thermal cycle, ${ }^{21-23}$ which was supported by direct temperature measurement inside the friction stir-processed region via in situ time-resolved neutron diffraction measurements. ${ }^{24-26}$ The thermocouple wires were embedded in predrilled channels and were attached to the end of the channel near the inner surface of the die hole. Temperature data were collected from positions at $7.62 \mathrm{~mm}, 22.86 \mathrm{~mm}, 50.8 \mathrm{~mm}$, and $76.2 \mathrm{~mm}$ beneath the top surface of the die as shown in Fig. 1a.

The FSBE experiments consisted of two plunging steps. In the first plunging step, the tool rotated at $500 \mathrm{RPM}$ and advanced at a rate of $63.5 \mathrm{~mm} / \mathrm{min}$ to a depth of $31.75 \mathrm{~mm}$ followed by a second step at a rate of $76.2 \mathrm{~mm} / \mathrm{min}$ to a depth of $86 \mathrm{~mm}$. 


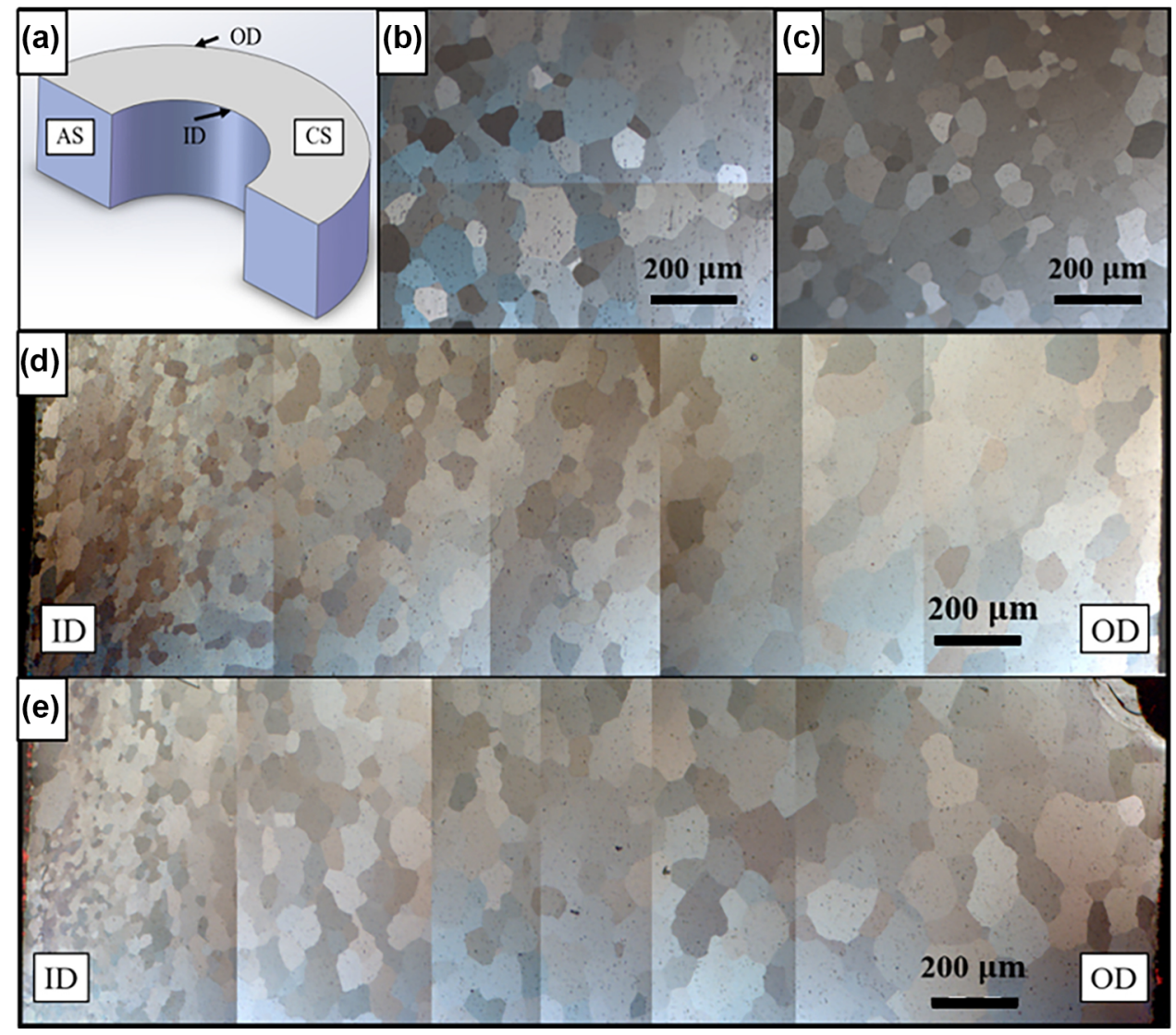

Fig. 2. Optical micrographs of 6063 alloy. (a) Schematic drawing of the characterized cross section. LS: longitudinal section; TS: transverse section. (b) Longitudinal view and (c) transverse view of the as-received material. (d) Longitudinal view of the extrudate. (e) Transverse view of the extrudate.

\section{Microhardness and Microstructure Charac- terization}

The hardness test and microstructure characterization of the extruded tubes were performed on both the transverse section, which is perpendicular to the tube axis (labeled "TS" in Fig. 2a), and the longitudinal section, which is along the tube axis (labeled "LS" in Fig. 2a). The metallographic samples were polished and etched using Barkers reagent to reveal the grain structure. Optical micrographs were taken by a Nikon MA700 Eclipse metallurgy microscope with a polarized light source. A JEOL JSM-6500F scanning electron microscope with EDS and EBSD detectors was used to study the grain orientation, boundaries, and composition of secondary phases. EDS was done at $20 \mathrm{kV}$ and $65 \mu \mathrm{A}$. For EBSD, the scan step was $1 \mu \mathrm{m}$ at $30 \mathrm{kV}$. Vickers hardness mapping was conducted on both the transverse and longitudinal sections using a LECO LM100 AT microhardness tester at $10 \mathrm{~g}$ load and $75 \mu \mathrm{m}$ spacing between indentations. XRD was conducted on both the original feedstock material and the extruded tubes using $\mathrm{Cu} \mathrm{Ka}$ radiation $(\lambda=1.54 \AA, 45 \mathrm{kV}, 40 \mathrm{~mA})$. Grain structures of the extruded tubes with a 17.5-OD mm plunger were revealed by electropolishing in a commercial electropolishing solution for aluminum from $\mathrm{SiC}$ Technologies (EP8537) at $65^{\circ} \mathrm{C}$ for $1-2 \mathrm{~min}$.

\section{RESULTS AND DISCUSSION}

\section{Temperature and Process Conditions}

Several tubes were extruded using the process conditions described in "Experimental" section. The initial hollowed feedstock tubes were $82.55 \mathrm{~mm}$ (3.25 inches) long. The extruded tubes were $\sim 95.25$ $\mathrm{mm}$ (3.75 inches) long. The extrusion ratio was 1.15. The motion and force data were collected by the FSE system. The plunge force and torque reached and stabilized at $\sim 1200 \mathrm{~N}$ and $\sim 110 \mathrm{~N} \cdot \mathrm{m}$, respectively.

The temperature data during the FSBE test were collected at a rate of $5 \mathrm{~Hz}$ with a dedicated temperature acquisition system. The relationship of the temperature with respect to the tool's position is shown in Fig. 1b. At the distance $1 \mathrm{~mm}$ from the die/ extrudate interface, the peak temperature was $\sim 50^{\circ} \mathrm{C}$ higher than that at the distance of $1.5 \mathrm{~mm}$ (i.e., $0.5 \mathrm{~mm}$ further away) at the same depth. The highest measured temperature in the die was $550.7^{\circ} \mathrm{C}$ at both the $22.86 \mathrm{~mm}$ and $50.8 \mathrm{~mm}$ positions from the top of the die and $1 \mathrm{~mm}$ to the die/ extrudate interface. It was higher than the 

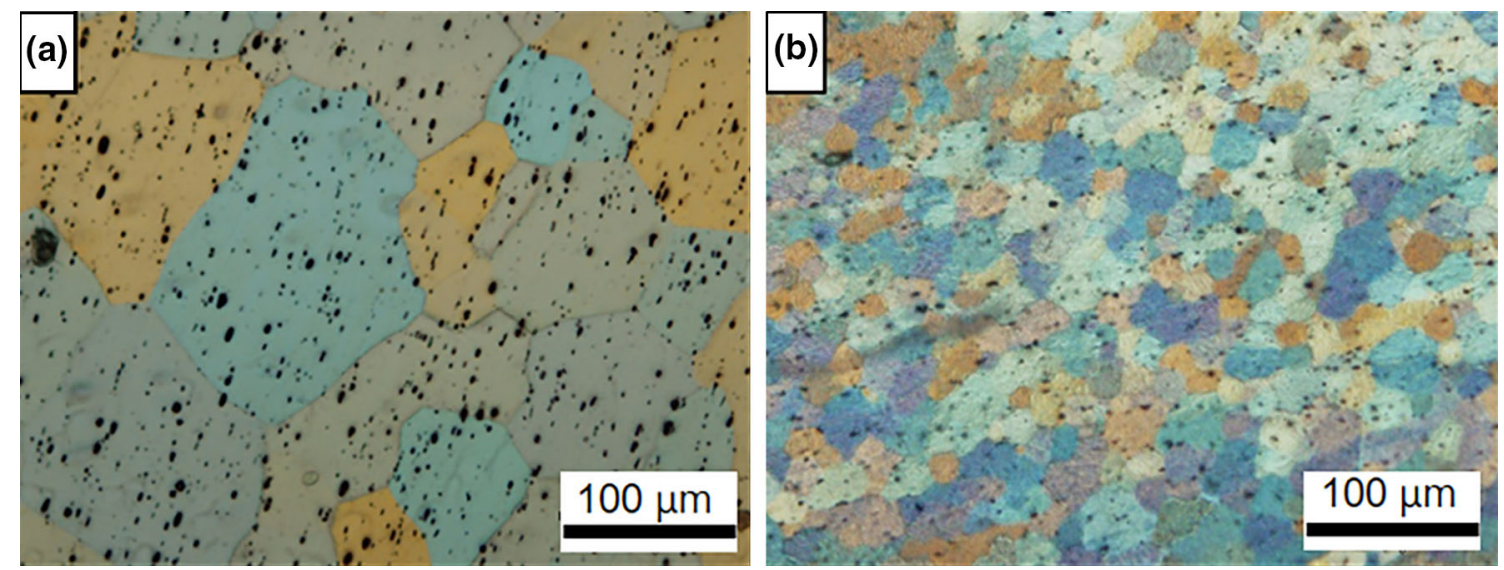

Fig. 3. Optical micrographs of 6063 alloy extrusion with a larger diameter tool. (a) Transverse view of as-received material; the mean grain size is $50 \pm 3 \mu \mathrm{m}$. (b) Transverse view of the center region of the extruded tube; the mean grain size is $18 \pm 2 \mu \mathrm{m}$.

precipitate dissolution temperature $\left(521^{\circ} \mathrm{C}\right)$ but below the $616^{\circ} \mathrm{C}$ solidus temperature and $654^{\circ} \mathrm{C}$ liquidus temperature 6063 aluminum alloy. ${ }^{27}$ It was expected that the temperature inside the extrudate and at the interface of the extruding tool (the plunger) and the $6063 \mathrm{Al}$ alloy would be $>550^{\circ} \mathrm{C}$. On the other hand, the relatively high plunging force and processing torque suggested that massive or bulk melting of 6063 was unlike that during the FSBE experiment in this study. We also noted that the temperature at the measured locations lasted $\sim 20 \mathrm{~s}$ over $520^{\circ} \mathrm{C}$, the dissolution temperature of the precipitates. It was then cooled down naturally to room temperature. The effect of temperature on grain size and microstructure will be discussed in "Microstructure characterization" and "Microhardness mapping" sections.

\section{Microstructure Characterization}

\section{Optical Microscope Imaging}

The optical microscope images of the etched materials are shown in Fig. 2 for the extruded tubes made with a $16-\mathrm{mm}$ plunger and in Fig. 3 for those with a $17.5-\mathrm{mm}$ plunger. Figure $2 \mathrm{~b}$ and $\mathrm{c}$ shows the original grain structure of the as-received $6063 \mathrm{Al}$ alloy. The grain sizes of the as-received material were measured using ImageJ software ${ }^{28}$ Grain size and morphology of the as-received material were similar on the longitudinal and transverse sections. Most of the grains were in the size range of 50 $120 \mu \mathrm{m}$; the average grain size was $53.72 \mu \mathrm{m}$. The average grain diameter calculated by the EBSD graph was $58.2 \mu \mathrm{m}$

Figure $2 \mathrm{~d}$ and e shows the grain structure of the extruded tubes from transverse and longitudinal sections, respectively. Considerable grain refinement was observed near the tube ID surface with an average grain size of $20.6 \mu \mathrm{m}$ The grain size and morphology near the ID surface were similar to the recrystallized grain structure in an FSW nugget zone reported by Sato et al., ${ }^{29}$ therefore suggesting that the frictional heating and server plastic deformation expected in this region of the inner wall in our FSBE experiment setup would lead to dynamic recrystallization as in the case of the stir zone of FSW. A gradual transition in grain size could be seen from the ID to OD of the extruded tubes. It was noted that the grain size near the OD surface was larger than that of the as-received, indicating grain growth in this region under the FSBE experimental conditions applied in the present study.

Figure $3 \mathrm{a}$ and $\mathrm{b}$ shows the typical grain structure before and after the FSBE process with the larger 17.5-mm diameter tool. The grain size was determined using the circular intercept procedure per ASTM E112-12. The mean grain size of the asreceived material was $50 \pm 3 \mu \mathrm{m}$, close to the measured values using the ImageJ software. As shown in Fig. 3b, the grain structure of the extrude tubes had a smaller mean grain size of $18 \pm 2 \mu \mathrm{m}$, depicting an improved grain refinement by increasing the tool's diameter.

\section{Energy-dispersive $x$-ray spectroscopy}

Figure 4 shows the precipitate distribution of the extruded tube using the smaller $16-\mathrm{mm}$-diameter tool. Figure $4 \mathrm{a}$ shows the results near the interface between the tool and extruded tube. The uniformly distributed light-colored particles of $2-5 \mu \mathrm{m}$ size (marked by white arrows) were identified as intermetallic precipitates. 6063 alloy is an $\mathrm{Al}-\mathrm{Mg}-\mathrm{Si}$ alloy system with $\mathrm{Fe}$ up to 0.35 wt.\%. $\mathrm{Mg}-\mathrm{Si}$ and AlFeSi intermetallic phases are the main precipitations in the material. One of the particles shown under higher magnification in Fig. 4b was further analyzed by EDS. Figure 4c shows the EDS spectrum of the area within the red rectangle in Fig. $4 \mathrm{~b}$. Relatively high concentrations of $\mathrm{Fe}(6.99$ at.\%) and $\mathrm{Si}(4.57$ at.\%) were measured in the particle, compared with measurements of 0.07 at. $\% \mathrm{Fe}$ and 0.43 at.\% Si in the adjacent dark-colored aluminum grain matrix. Element mappings of the region in Fig. $4 \mathrm{~b}$ are shown as Fig. 4d, e, and f, respectively, 


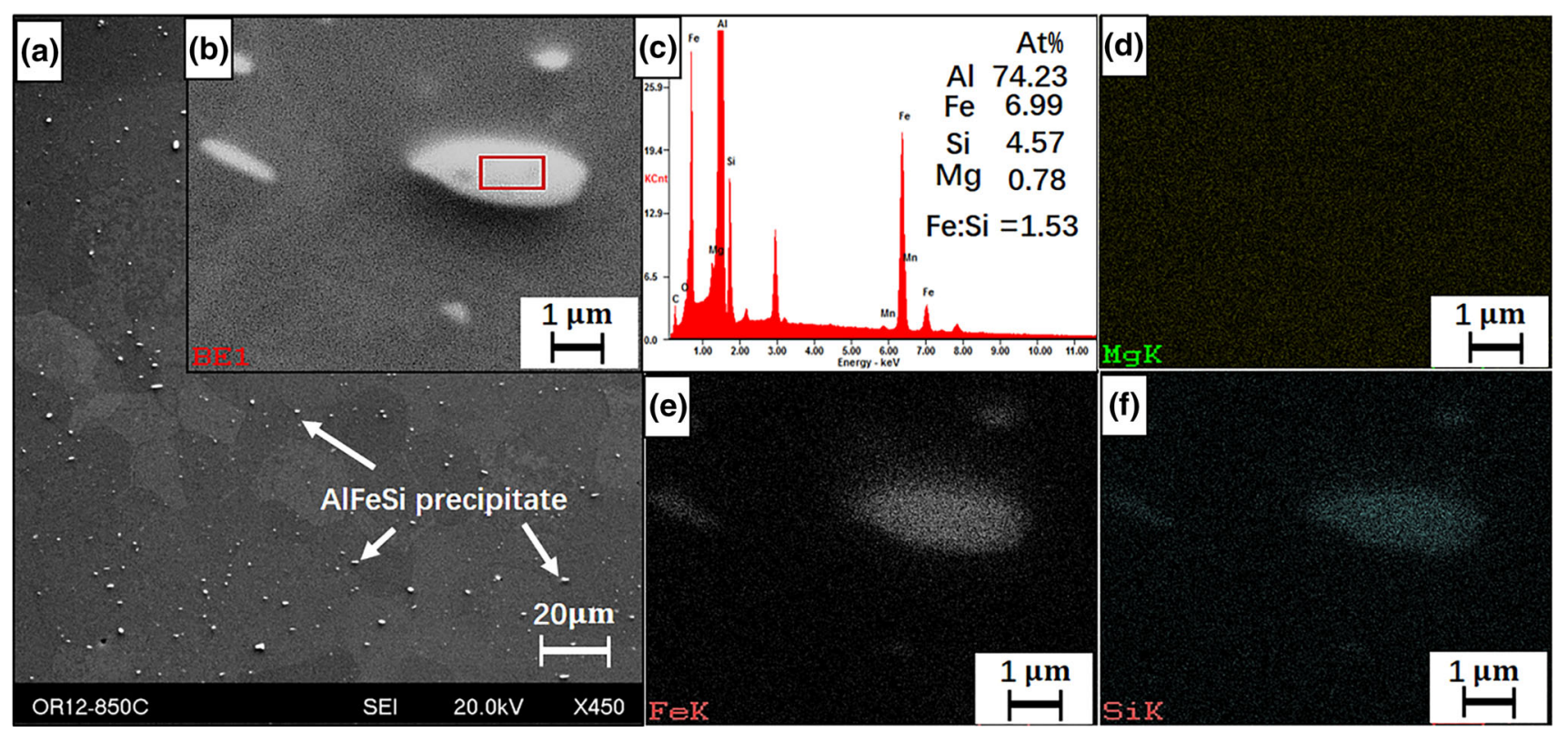

Fig. 4. EDS results of the ID region of the extruded tube: (a) white arrows indicate AIFeSi particles in the material; (b) higher magnification view of the AIFeSi precipitates; (c) EDS spectrum of the red rectangle zone marked in (b); element mapping of (d) magnesium, (e) iron and (f) silicon of the region in (b).

Table I. $2 \theta$ of the x-ray diffraction peaks of the original material and FSBE extrudate

\begin{tabular}{|c|c|c|}
\hline $\begin{array}{l}\text { Miller } \\
\text { indices }\end{array}$ & $\begin{array}{c}\text { Original } \\
\text { material/ }\end{array}$ & $\begin{array}{c}\text { FSBE } \\
\text { extrudate/ }^{\circ}\end{array}$ \\
\hline Al 111 & 38.5325 & 38.4373 \\
\hline $\mathrm{Al} 200$ & 44.7549 & 44.6816 \\
\hline Al 220 & 65.1113 & 65.0290 \\
\hline $\mathrm{Al} 311$ & 78.2041 & 78.1381 \\
\hline
\end{tabular}

for $\mathrm{Mg}, \mathrm{Fe}$, and $\mathrm{Si}$, which also revealed enrichment of $\mathrm{Fe}$ and $\mathrm{Si}$. Similar results were obtained from multiple precipitations. The ratio of $\mathrm{Fe}: \mathrm{Si}$ was determined as 1.57. Therefore, the precipitation was identified as $\alpha \mathrm{AlFeSi}$ precipitation, according to Refs. 30 and 31 .

$\mathrm{Mg}-\mathrm{Si}$ intermetallic $\left(\beta^{\prime \prime}, \beta^{\prime}\right)$ are the major strengthening phases of the 6063 aluminum alloy. ${ }^{29,32,33}$ As the 6063 experiences a peak temperature higher than its dissolution temperature in FSBE, as measured in this study, it was expected that the Mg-Si intermetallic precipitates would be dissolved in the experiment, similar to the same observation of precipitate dissolution during friction stir welding. ${ }^{29,34,35}$ Previous studies detected Mg-Si precipitate particles of $100-500 \mathrm{~nm}$ size in T6 heattreated 6061 and 6063 alloy, ${ }^{36-38}$ while no $\mathrm{Mg}-\mathrm{Si}$ precipitation was identified from the EDS test of the processed material. The x-ray diffraction (XRD) measurement performed on the as-received material and extruded material corroborated this assessment. As shown in Table I, the lattice spacing of the extruded material was larger (4.052 $\AA$ ) than that of as-received samples (4.046 $\AA$ ), which indicates lattice expansion of the extruded materials as a result of supersaturation of $\mathrm{Mg}$ and $\mathrm{Si}$ in the matrix.

\section{Electron Backscattering Diffraction}

Figure 5 shows the EBSD pattern of the original feedstock $6063 \mathrm{Al}$ alloy. OIM analysis 7 software (EDAX Inc.) was used to collect data for the grain size, boundaries, and misorientation. Figure 5a is an orientation map based on the [001] inverse pole figure (IPF) of the as-received material on the longitudinal section. Figure 5b shows the grain boundary map colored with the kernel average misorientation (KAM) of the same area. Low-angle grain boundaries (LAGBs) $\left(2^{\circ}-15^{\circ}\right)$ and high-angle grain boundaries (HAGBs) (above $15^{\circ}$ ) are plotted with green and black lines in Fig. 5b. LAGBs were considered subgrain structures, and the average grain diameter was calculated by software using HAGBs to identify the grains. The average grain diameter was $59.18 \mu \mathrm{m}$ with a $27.33 \mu \mathrm{m}$ standard deviation.

Figure $6 \mathrm{a}, \mathrm{b}$, and $\mathrm{c}$ shows the orientation maps based on the [001] inverse pole figures near the plunging tool interface [i.e., inner diameter zone (IDZ)], at the half wall thickness (HWTZ), and near the die interface [i.e., outer diameter zone (ODZ)] on the longitudinal section. Figure $6 \mathrm{~d}-\mathrm{f}$ shows the grain boundary maps colored with KAM of the same zones. The parameters used to characterize the grain elongation direction, the average grain angles in Fig. $6 \mathrm{a}$, were $12.1^{\circ}, 11.7^{\circ}$, and $13.2^{\circ}$ at the IDZ, HWTZ, and ODZ zones, respectively. ${ }^{39} \mathrm{~A}$ small average grain angle indicates that the major axis of 

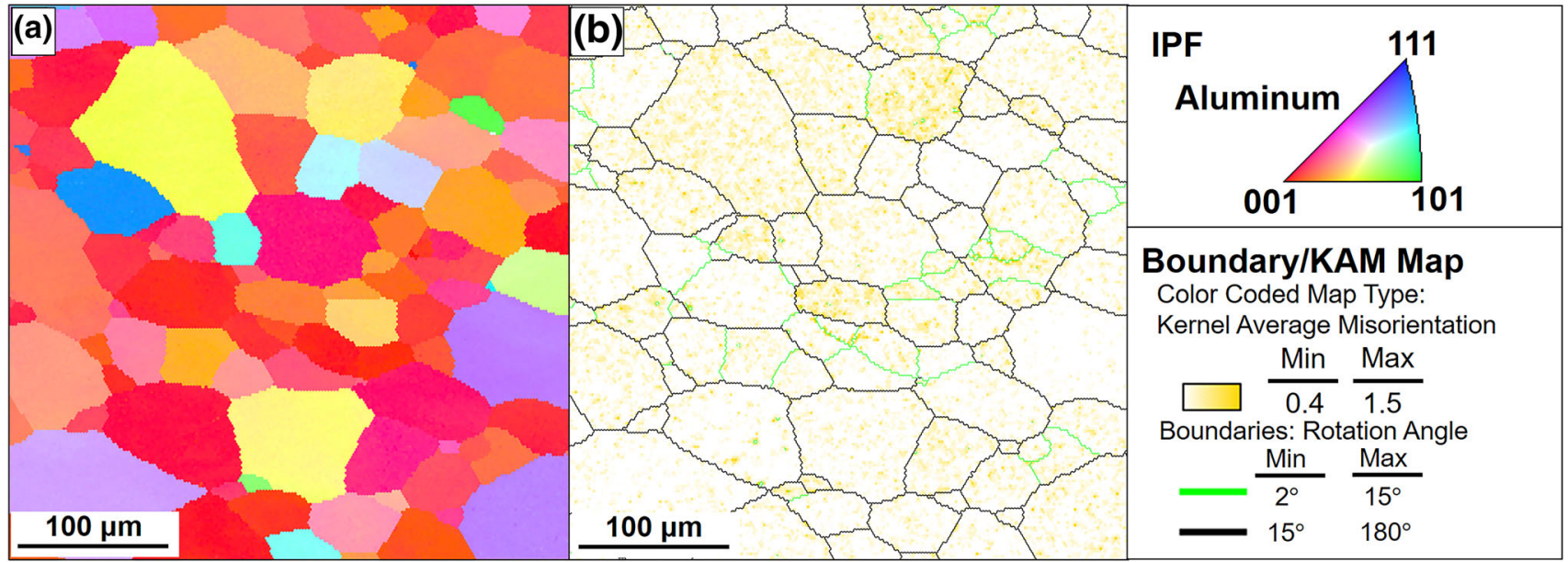

Fig. 5. EBSD image of the original as-received material: (a) orientation map colored by a [001] inverse pole figure (IPF) and (b) phase distribution and grain boundaries. Right: The legends list the color code of IPFs and phase-boundary maps.

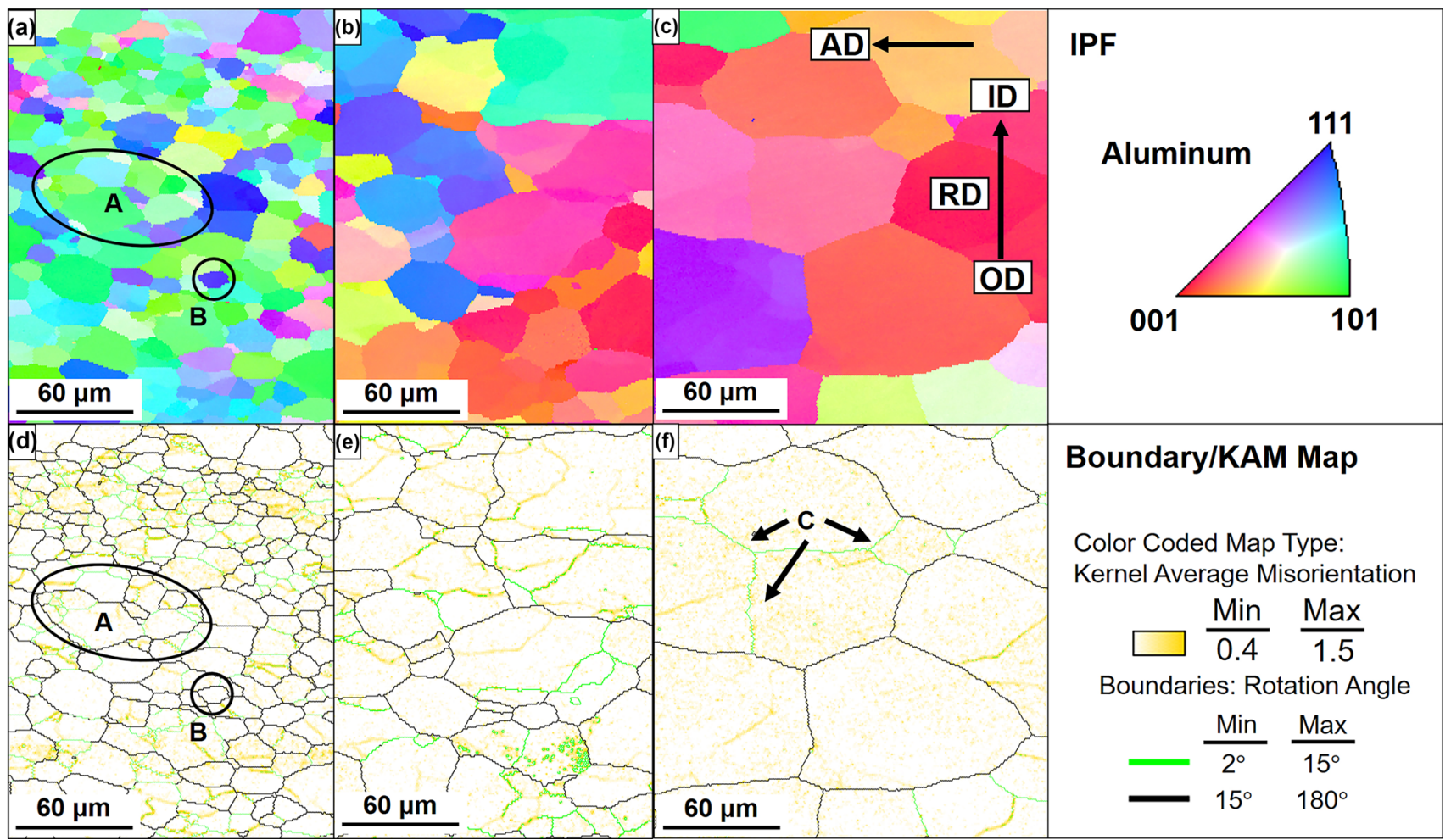

Fig. 6. EBSD images of the extruded tube: [001] inverse pole figure (IPF) image of (a) IDZ, (b) HWTZ, and (c) ODZ; boundary maps of (d) IDZ, (e) HWTZ, and (f) ODZ. Circle A highlights a recrystallized grain. Circle B highlights a grain with LAGB from DRV. AD: axial direction, RD: radial direction. RD arrow points at the direction from OD to ID.

the grain preferably aligns to the images' horizonal direction, which is also the circumferential direction of the tube. Grains shown in Fig. 6 are slightly elongated along the axial direction (denoted as 'AD' in Fig. 5) of the tube, likely related to the fact that the material is sheared in the out-of-plane direction and compressed in the radial direction (denoted as 'RD' in Fig. 5) as the rotating tool processes the tube's ID.
The FSBE process in this research produced an equiaxed grain structure, which is commonly seen in other published FSBE studies. 5,6,9,10 Globular grains are dominant in the extrudate microstructure. The average grain size from the EBSD measurement is consistent with that obtained optically shown in Fig. 2: the grain size gradually increases from $20.6 \mu \mathrm{m}$ at IDZ, $58.5 \mu \mathrm{m}$ at HWTZ, and $89.1 \mu \mathrm{m}$ at ODZ. The tube ID grain refinement can 


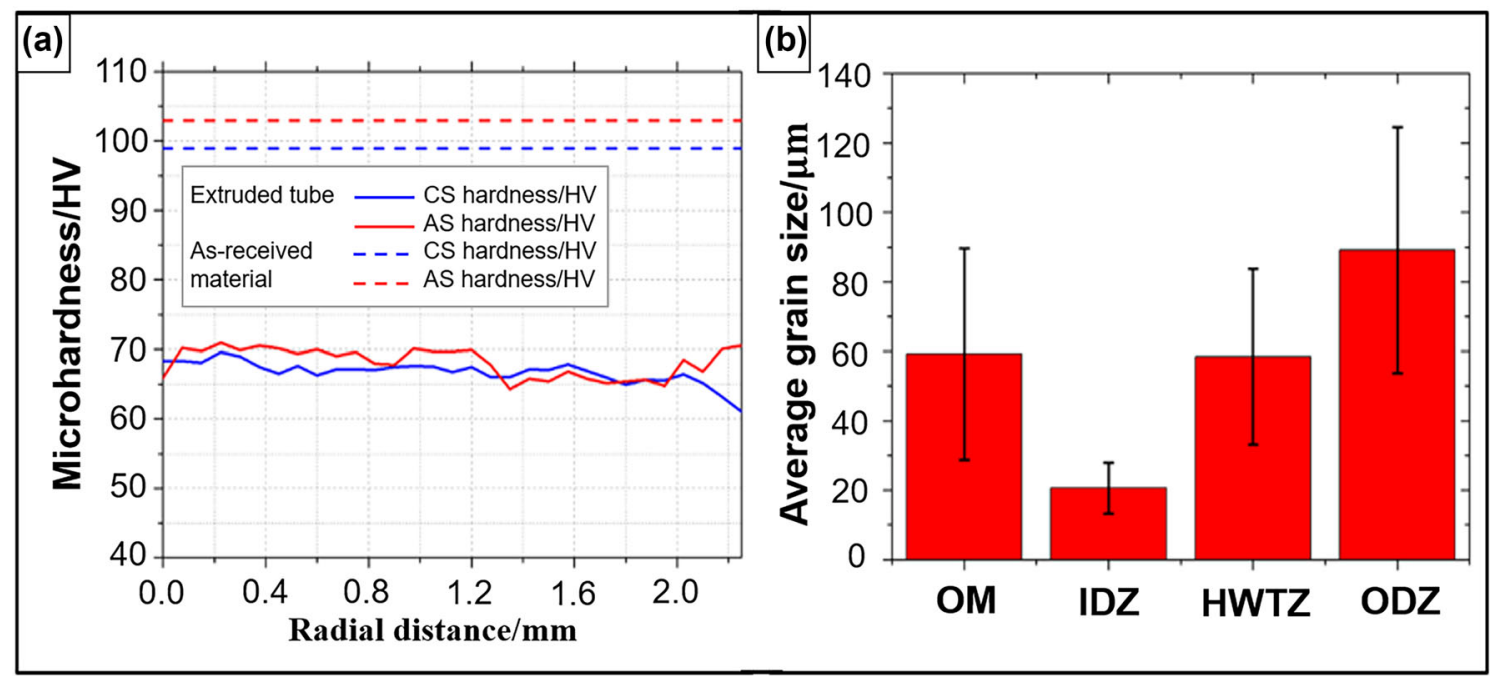

Fig. 7. (a) Microhardness value along the radial distance of the cross sections. (b) Histogram of the average grain size (red bar) and standard deviation (error bar) from the longitudinal view calculated by EBSD analysis software at different positions. OM: original material; IDZ, HWTZ, and ODZ of the extrudate.

be attributed to the dynamic recovery (DRV) and dynamic recrystallization (DRX). During the plastic deformation under a high enough temperature ( $>40 \%$ of the melting temperature of the material), dislocations inside the grain are annihilated or rearranged to form LAGBs by dislocation glide, climb, and cross-slip. Globular subgrain structures are formed with LAGB separation of the grain. ${ }^{40,41}$ As the extent of deformation increases, subgrains become smaller individual grains via two possible mechanisms: continuous dynamic recrystallization (CDRX) and geometric dynamic recrystallization (GDRX). ${ }^{42,43}$ Discontinuous dynamic recrystallization is not likely to happen in aluminum or its alloys because of its high stacking fault energy. ${ }^{44}$ The transition of the grain diameter in different areas may be due to variations in deformation history. In IDZ (see Fig. 6d), the strain input was large enough to produce refined grains by CDRX (typical grains are highlighted in the circle labeled A); some grains retained their initial size with subgrains inside via the DRV process in IDZ (highlighted in the circle labeled B). Large fractions of LAGBs (0.209 from the longitudinal view and 0.237 from the transverse view) and subgrains in IDZ indicate an incomplete grain refinement in the region. In HWTZ, only grains whose size is comparable to the size of grains in the original as-received material and LAGB by DRV are present because the strain input was insufficient in the area. The ODZ experienced a grain growth $(89.1 \mu \mathrm{m})$ compared with the grain size in the initial microstructure. With the FSBE experimental setup in this present work, it is expected that there was minimal shear strain at the ODZ, as most of the frictional heating and shear deformation between the rotating tool and the 6063 $\mathrm{Al}$ alloy took place at the ID surface of the $\mathrm{Al}$ tube.
On the other hand, the ODZ reached a peak temperature $>550^{\circ} \mathrm{C}$, according to the temperature measurement. This high temperature would result in grain growth. LAGB marked by the arrow ' $\mathrm{C}$ ' in Fig. $6 \mathrm{f}$ indicates that smaller grains in the asreceived material merged into coarse grains. HAGB was turned into LAGB by the rearrangement of dislocation. $^{29,45,46}$ Grain refinement in our FSBE process is limited to the inner surface of the extruded tube, resulting in considerable variations of grain sizes through the tube wall thickness.

\section{Microhardness Mapping}

The results of microhardness tests are shown in Fig. 7a. The average hardness measured on the original as-received billet had an average microhardness of HV 90-95, which is typical for the T6 aging condition of the 6063 alloy. The hardness of the extruded tube is in the range of HV 60-75, which is equivalent to the T4-T5 aging condition and higher than that of the completed supersaturated solid solution situation (HV 40-50). ${ }^{47}$ Despite the considerable grain size variations, the microhardness is evenly distributed from OD to ID with minor deviation. The hardness values in the extruded tubes are very similar to hardness in the thermal-mechanical affected zones of FSW with similar thermal cycles as reported in Refs. 29, 48, and 49 .

The effect of the grain size on hardness is not significant for precipitate-hardening alloys. ${ }^{50,51} \mathrm{An}$ estimation of a difference in grain size-induced hardness in the ODZ and IDZ can be expressed using the Hall-Petch relationship: ${ }^{52}$

$$
\Delta H=k \cdot\left(D_{\mathrm{ID}}^{-\frac{1}{2}}-D_{\mathrm{OD}}^{-\frac{1}{2}}\right)
$$


where the $\Delta H$ is the microhardness difference and $D_{\mathrm{ID}}$ and $D_{\mathrm{OD}}$ are the grain sizes of IDZ and ODZ. Average grain diameters $(20.6 \mu \mathrm{m}$ and $89.1 \mu \mathrm{m}$ at IDZ and ODZ, respectively) are used in this case. Taking the appropriate value of the constant $(k)$, which is $\sim 40 \mathrm{HV} \cdot \mu \mathrm{m}^{1 / 2}$ in the literature, ${ }^{53}$ the difference in grain sizes in the present study would result in a maximum hardness difference of approximately $4.4 \mathrm{HV}$. This explains the relatively even hardness variation through the wall thickness despite the considerable changes in the grain size change.

\section{CONCLUSION}

A specially FSBE experimental setup was utilized to purposely introduce a deformation gradient through the wall thickness of the friction stir back-extruded 6063-T6 alloy tubes. The frictional heating and severe plastic deformation associated with FSBE were largely limited to the inner surface of the extruded tubes. Under the FSBE conditions in the present study, gradual grain size changes took place from the inner to outer surface. The asreceived material had globular grains with an average diameter of 50-60 $\mu \mathrm{m}$. Refined grains with $\sim 20 \mu \mathrm{m}$ average diameter were formed near the inner tube wall surface because of dynamic recovery and recrystallization. On the other hand, considerable grain growth up to $\sim 90 \mu \mathrm{m}$ from $50 \mu \mathrm{m}$ of the as-received material was observed near the outer tube wall surface, attributed to thermally driven grain growth.

The friction stir back-extruded tube had a uniform microhardness distribution through the wall thickness. The microhardness was reduced to $\mathrm{HV}$ 60-75 in the extruded tubes from HV 90-95 of the as-received materials under T6 heat treatment conditions, which can be attributed to the relatively high extrusion temperature exceeding $550^{\circ} \mathrm{C}$ over the entire tube wall to cause complete dissolution of the $\mathrm{Mg}-\mathrm{Si}$ intermetallic precipitates during the extrusion and uniform re-precipitation (natural aging) during the subsequent cooling.

\section{ACKNOWLEDGEMENTS}

This work is supported by a lightweight-innovations-for-tomorrow (LIFT) project operated by the American Lightweight Materials Manufacturing Innovation Institute (ALMMMII), USA. The work is being conducted at Oak Ridge National Laboratory, Lockheed Martin Corporation, and the University of Notre Dame. Suhong Zhang appreciates the assistance and knowledge from Dr. Wei Tang and Dr. Zhengang $\mathrm{Wu}$ of ORNL for friction stir processing and metallurgy characterization. This manuscript has been authored by UT-Battelle LLC under Contract No. DE-AC05-00OR22725 with the US Department of Energy. The United States Government retains and the publisher, by accepting the article for publication, acknowledges that the Uni- ted States Government retains a non-exclusive, paid-up, irrevocable, world-wide license to publish or reproduce the published form of this manuscript, or allow others to do so, for United States Government purposes. The Department of Energy will provide public access to these results of federally sponsored research in accordance with the DOE Public Access Plan (http://energy.gov/downloads/do e-public-access-plan).

\section{OPEN ACCESS}

This article is distributed under the terms of the Creative Commons Attribution 4.0 International License (http://creativecommons.org/licenses/by/4.0/), which permits unrestricted use, distribution, and reproduction in any medium, provided you give appropriate credit to the original author(s) and the source, provide a link to the Creative Commons license, and indicate if changes were made.

\section{REFERENCES}

1. M. Bauser, G. Sauer, and K. Siegert, Extrusion, 2nd ed. (Materials Park, OH: ASM International, 2006), pp. 2-9.

2. W.M. Thomas, E.D. Nicholas, R.E. Dolby, C.J. Jones, and R.H. Lilley, International Patent, PCT/GB92/01540.21.8.92, 1992.

3. S. Whalen, N. Overman, V. Joshi, T. Varga, D. Graff, and C. Lavender, Mater. Sci. Eng. A 755, 278 (2019).

4. D. Baffari, A.P. Reynolds, A. Masnata, L. Fratini, and G. Ingarao, J. Manuf. Process. 43, 63 (2019).

5. Z. Feng, and K. Manchiraju, Report. No. DOE-SWIRE03458; Oak Ridge National Lab. (ORNL), Oak Ridge, TN, USA, 2012. https://doi.org/10.2172/1039705.

6. F. Abu-Farha, Scr. Mater. 66, 615 (2012).

7. W.M. Thomas, and E.D. Nicholas, Friction stir welding and friction extrusion of aluminium and its alloys, in 3rd World Congress on Aluminium, Limassol, Cyprus, 1997.

8. V.K. Manchiraju, Z. Feng, S.A. David, and Z. Yu, US Patent, US9616497 B2, 2017.

9. F. Abu-Farha, in ASME 2012 International Manufacturing Science and Engineering Conference collocated with the $40 t h$ North American Manufacturing Research Conference and in participation with the International Conference on Tribology Materials and Processing, American Society of Mechanical Engineers Digital Collection, p. 199 (2013).

10. W. Tang and A.P. Reynolds, J. Mater. Process. Technol. 210, 2231 (2010).

11. D. Baffari, G. Buffa, D. Campanella, L. Fratini, and A.P. Reynolds, J. Manuf. Process. 29, 41 (2017).

12. I. Dinaharan, R. Sathiskumar, S.J. Vijay, and N. Murugan, Proc. Mater. Sci. 5, 1502 (2014).

13. J.L. Milner, and F. Abu-Farha, Magnesium Techology 2014, ed. by M. Alderman, N. Hort, M.V. Manuel, N.R. Neelameggham. (Switzerland: Springer International Publishers, 2016), p. 497.

14. Y. Hangai, Y. Nakano, T. Utsunomiya, O. Kuwazuru, and N. Yoshikawa, J. Mater. Eng. Perform. 26, 894 (2017).

15. Y. Hangai, S. Otazawa, and T. Utsunomiya, Compos. Struct. 183, 416 (2018).

16. X. Li, W. Tang, A.P. Reynolds, W.A. Tayon, and C.A. Brice, J. Mater. Process. Technol. 229, 191 (2016).

17. X. Li, W. Tang, and A.P. Reynolds, in ICAA13 Pittsburgh: Proceedings of the 13th International Conference on Aluminum Alloys, ed. by H. Weiland, A.D. Rollett, W.A. Cassada. (Springer, 2012), p. 1659.

18. H. Zhang, X. Zhao, X. Deng, M.A. Sutton, A.P. Reynolds, S.R. McNeill, and X. Ke, Int. J. Mech. Sci. 85, 130 (2014).

19. H. Zhang, X. Li, W. Tang, X. Deng, A.P. Reynolds, and M.A. Sutton, J. Mater. Process. Technol. 221, 21 (2015). 
20. M.S. Khorrami and M. Movahedi, Mater. Des. 65, 74 (2015).

21. M.W. Mahoney, C.G. Rhodes, J.G. Flintoff, W.H. Bingel, and R.A. Spurling, Metall. Mater. Trans. A 29, 1955 (1998).

22. Y.J. Chao, X. Qi, and W. Tang, J. Manuf. Sci. Eng. 125, 138 (2003).

23. Megastir Co. fsw instrumented tool holder (Megastir Co. Web, 2018). https://megastir.com/kits/fsw-instrumented-too l-holder/, Accessed Aug 2019.

24. W. Woo, Z. Feng, X.-L. Wang, D.W. Brown, B. Clausen, K. An, H. Choo, C.R. Hubbard, and S.A. David, Sci. Technol. Weld. Joining 12, 298 (2007).

25. Z. Yu, Z. Feng, W. Woo, and S.A. David, JOM 65, 65 (2013).

26. W. Woo, Z. Feng, B. Clausen, and S.A. David, Mater. Lett. 196, 284 (2017).

27. J.E. Hatch, eds., Aluminum: properties and physical metallurgy (Metals Park, OH: ASM International, 1984), pp. $50-51$.

28. ASTM E112-96 (2004) e2. (ASTM International: West Conshohocken, PA, 2004).

29. Y.S. Sato, H. Kokawa, M. Enomoto, and S. Jogan, Metall. Mater. Trans. A 30, 2429 (1999).

30. S.R. Claves, D.L. Elias, and W.Z. Misiolek, Materials Science Forum. (Trans Tech Publications Ltd, 2002), p. 667.

31. P. Skjerpe, Metall. Mater. Trans. A 18, 189 (1987).

32. A.P. Sekhar, S. Nandy, K.K. Ray, and D. Das, J. Mater. Eng. Perform. 28, 2764 (2019).

33. S.K. Panigrahi and R. Jayaganthan, J. Mater. Sci. 45, 5624 (2010).

34. Y.S. Sato, H. Kokawa, M. Enomoto, S. Jogan, and T. Hashimoto, Metall. Mater. Trans. A 30, 3125 (1999).

35. B. Heinz and B. Skrotzki, Metall. Mater. Trans. B 33, 489 (2002).

36. G.A. Edwards, K. Stiller, G.L. Dunlop, and M.J. Couper, Acta Mater. 46, 3893 (1998).

37. G. Al-Marahleh, Met. Sci. Heat Treat. 48, 205 (2006).

38. G. Al-Marahleh, Am. J. Appl. Sci. 3, 1819 (2006).
39. J. Wu, P.J. Wray, C.I. Garcia, M. Hua, and A.J. DeArdo, ISIJ Int. 45, 254 (2005).

40. H.J. McQueen, Mater. Sci. Eng. A 387, 203 (2004).

41. H.-E. Hu, L. Zhen, B.-Y. Zhang, L. Yang, and J.-Z. Chen, Mater. Charact. 59, 1185 (2008).

42. S. Gourdet and F. Montheillet, Acta Mater. 51, 2685 (2003).

43. W. Blum, Q. Zhu, R. Merkel, and H.J. McQueen, Mater. Sci. Eng. A 205, 23 (1996).

44. K. Huang and R.E. Logé, Mater. Des. 111, 548 (2016).

45. K.J. Al-Fadhalah, A.I. Almazrouee, and A.S. Aloraier, $M a-$ ter. Des. 53, 550 (2014).

46. J.-Q. Su, T.W. Nelson, and C.J. Sterling, Mater. Sci. Eng. A 405, 277 (2005).

47. S.O. Adeosun, S.A. Balogun, O.I. Sekunowo, and M.A. Usman, J. Miner. Mater. Charact. Eng. 9, 763 (2010).

48. Y.S. Sato, M. Urata, and H. Kokawa, Metall. Mater. Trans. A 33, 625 (2002).

49. Y.S. Sato, S.H.C. Park, and H. Kokawa, Metall. Mater Trans. A 32, 3033 (2001).

50. I. Ansara, A.T. Dinsdale, and M.H. Rand. Al-Mg COST 507 Thermochemical database for light metal alloys (1998) htt ps://materialsdata.nist.gov/handle/11256/618, Accessed Oct 2018.

51. C.G. Rhodes, M.W. Mahoney, W.H. Bingel, R.A. Spurling, and C.C. Bampton, Scr. Mater. 36, 69-75 (1997).

52. Y.S. Sato, M. Urata, H. Kokawa, and K. Ikeda, Mater. Sci. Eng. A 354, 298 (2003).

53. H. Hasegawa, S. Komura, A. Utsunomiya, Z. Horita, M. Furukawa, M. Nemoto, and T.G. Langdon, Mater. Sci. Eng. A 265, 188 (1999).

Publisher's Note Springer Nature remains neutral with regard to jurisdictional claims in published maps and institutional affiliations. 